\title{
INTRAPERITONEAL BUPIVACAINE ALONE WITH DEXMEDETOMIDINE OR TRAMADOL FOR POSTOPERATIVE ANALGESIA FOLLOWING LAPAROSCOPIC CHOLECYSTECTOMY - A COMPARATIVE EVALUATION
}

\author{
Ummer Ali', Mohamad Ommid², Nazia Shafiya Alamgir ${ }^{3}$, Sheeba Nazir ${ }^{4}$, Reyaz Lone $^{5}$, Arshi Taj ${ }^{6}$, Humera Manzoor $^{7}$, Farhana Bashir $^{8}$
}

${ }^{1}$ Senior Resident, Department of Anaesthesiology, GMC, Srinagar.

${ }^{2}$ Assistant Professor, Department of Anaesthesiology, GMC, Srinagar.

3 Junior Resident, Department of Emergency Medicine, SKIMS Medical College, Srinagar.

${ }^{4}$ Medical Officer, Directorate of Health Services, Srinagar.

${ }^{5}$ Consultant, Paediatric Cardiac Surgery Surgeon, HMC, Doha.

${ }^{6}$ Assistant Professor, Department of Anaesthesiology, GMC, Srinagar.

${ }^{7}$ Lecturer, Department of Anaesthesiology, GMC, Srinagar.

${ }^{8}$ Lecturer, Department of Anaesthesiology, GMC, Srinagar.

\begin{abstract}
BACKGROUND

Post laparoscopic cholecystectomy patients complain more of visceral pain as a result of stretching of the intra-abdominal cavity, peritoneal inflammation and phrenic nerve irritation caused by residual carbon dioxide in the peritoneal cavity. Intraperitoneal instillation of local anaesthetic agents has become an important method to control postoperative pain, nausea, vomiting and reduced hospital stay. The purpose of this double-blinded randomised controlled trial was to compare the analgesic efficacy of intraperitoneal instillation of local anaesthetic agents alone or in combination with opioids, $\propto-2$ agonists such as clonidine and dexmedetomidine to reduce postoperative pain following laparoscopic cholecystectomy.
\end{abstract}

\section{MATERIALS AND METHODS}

135 were equally divided into three, allocated to one of the groups by random allocation cards using computer generated rando $m$

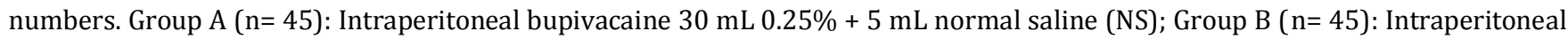
bupivacaine $30 \mathrm{~mL} 0.25 \%$ + tramadol $1 \mathrm{mg} / \mathrm{kg}$ (diluted in $5 \mathrm{~mL} \mathrm{NS}$ ); or Group C ( $\mathrm{n}=45)$ : Intraperitoneal bupivacaine $30 \mathrm{~mL} 0.25 \%$ + dexmedetomidine $1 \mathrm{mcg} / \mathrm{kg}$ (diluted in $5 \mathrm{~mL} \mathrm{NS}$ ).

\section{RESULTS}

We found bupivacaine in combination with tramadol (Group B) has significantly lower VAS score at all points of time (P $<0.001$ ) and overall VAS score and postoperative analgesia was statistically lower than with Group A. But bupivacaine + dexmedetomidine had even better VAS score underlying high efficacy of drug. Time to first request of analgesia in postoperative period was significantly delayed in Group C as compared to Group A ( $\mathrm{P}=0.86)$.

\section{CONCLUSION}

We conclude that intraperitoneal instillation of dexmedetomidine $1 \mathrm{mcg} / \mathrm{kg}$ in combination with bupivacaine $0.25 \%$ in elective laparoscopic cholecystectomy significantly reduces the postoperative pain and significantly reduces the analgesic requirement in postoperative period as compared to bupivacaine $0.25 \%$ alone and may be better than bupivacaine combined with tramadol.

\section{KEYWORDS}

Laparoscopy, Bupivacaine, Dexmedetomidine, Tramadol, VAS Analgesia.

HOW TO CITE THIS ARTICLE: Ali U, Ommid M, Alamgir NS, et al. Intraperitoneal bupivacaine alone with dexmedetomidine or tramadol for postoperative analgesia following laparoscopic cholecystectomy- a comparative evaluation. J. Evolution Med. Dent. Sci. 2017;6(90):6373-6380, DOI: 10.14260/jemds/2017/1386

\section{BACKGROUND}

Postoperative pain management remains a major challenge after laparoscopic procedures. Effective pain control encourages early ambulation, which significantly reduces the risk of deep vein thrombosis and pulmonary emboli (PE); enhances patient's ability to take deep breaths to decrease the risk of pulmonary complications (e.g. atelectasis and

'Financial or Other Competing Interest': None.

Submission 04-08-2017, Peer Review 04-11-2017,

Acceptance 11-11-2017, Published 20-11-2017.

Corresponding Author:

Dr. Mohamad Ommid,

Assistant Professor

Department of Anaesthesiology and Critical Care,

Government Medical College, Srinagar, J\&K, India

E-mail:ommid76@yahoo.com

DOI: $10.14260 /$ jemds $/ 2017 / 1386$ pneumonia); and decreases the incidence of tachycardia and unnecessary investigations related to it.1 Postoperative pain may be transient and most of the time lasts for 24 hours and sometimes even up to 3 days. Intensity of pain is more immediately after surgery and less after 24 hours. There are certain more complications like postoperative nausea and vomiting, which are more in first 24 hours. This pain can be reduced by the use of local anaesthetics, non-steroidal antiinflammatory drugs and other analgesics as well. Local anaesthetics can be given as epidural, intraperitoneal or as infiltration around the laparoscopic port sites before and after surgery. ${ }^{2-6}$ Currently, the standard treatment for acute postoperative pain is the use of systemic opioids. Opioids bind to specific receptors located throughout the central nervous system and other tissues. Unfortunately, opioids are not without complications. Drowsiness, nausea, vomiting, 
ileus, urinary retention and pruritus are all side effects of opioids. These side effects can lead to longer lengths of stays and poor patient outcomes.7,8,9 Another approach to control postoperative pain and limit postoperative opioid usage is local anaesthetic wound infiltration prior to wound closure. Several studies have applied both models and administered local anaesthetic, both prior to and at closure.10-14

Injecting local anaesthetics prior to surgical incision into the surgical wound has been more extensively studied. The results in this area are mixed with several studies showing significant pain reduction. ${ }^{15-21}$ Intraperitoneal instillation of local anaesthetic agents alone or in combination with opioids, $\propto-2$ agonists such as clonidine and dexmedetomidine have been found to reduce postoperative pain following laparoscopic cholecystectomy.22-25 After laparoscopic cholecystectomy, patients complain more of visceral pain as a result of stretching of the intra-abdominal cavity, peritoneal inflammation and phrenic nerve irritation caused by residual carbon dioxide in the peritoneal cavity, whereas after open cholecystectomy the type of pain results mostly in parietal pain. ${ }^{26}$ Postoperative abdominal pain usually occurs during the first 24 hours, while shoulder pain most commonly appears the second day after laparoscopic cholecystectomy. Intraperitoneal (IP) administration of some laparoscopic surgery. Some authors suggest that intraperitoneal instillation of drugs for pain relief is effective if used before creation of pneumoperitoneum, ${ }^{27}$ while others conclude that intraperitoneal drug administration is effective at the end of the surgery applied through a trocar. 28

Pain after laparoscopic surgery has a visceral component as a result of surgical handling and a somatic component due to the holes made in the abdominal wall for the trocars. Shoulder pain, which is associated with peritoneal insufflation occurs especially when shoulder holders and an exaggerated Trendelenburg position are used that frequently complicate the postoperative period after the laparoscopic surgery. Various methods have been tried to relieve postoperative pain following laparoscopic procedures. IP local anaesthetics (IPLAs) alone or in combination with non-opioid analgesics have been used to reduce postoperative pain following laparoscopy. This might reduce adverse effects of opioids and postoperative pain as well. ${ }^{29,30}$

\section{Aims of the Study}

The purpose of this double-blinded randomised controlled trial was to compare the analgesic efficacy of intraperitoneal instillation of local anaesthetic agents alone or in combination with opioids, $\propto-2$ agonists such as clonidine and dexmedetomidine to reduce postoperative pain following laparoscopic cholecystectomy in terms of time to first request of analgesia, total dose of analgesia in the first 24 hours and adverse effects.

\section{MATERIALS AND METHODS}

Design

Double-blinded randomised controlled trial.

\section{Study Period}

2 years.

\section{Sampling}

135 patients ASA class I and II admitted for laparoscopic cholecystectomy in GMC, Srinagar.

\section{Sampling Procedure}

Patients were randomly allocated using random allocation cards using computer generated random numbers to one of the groups using table of randomisation, Group A ( $n=45)$ : Intraperitoneal bupivacaine $30 \mathrm{~mL} 0.25 \%+5 \mathrm{~mL}$ normal saline (NS), Group B ( $\mathrm{n}=45)$ : Intraperitoneal bupivacaine 30 $\mathrm{mL} 0.25 \%$ + tramadol $1 \mathrm{mg} / \mathrm{kg}$ (diluted in $5 \mathrm{~mL} \mathrm{NS}$ ) or Group C ( $\mathrm{n}=45)$ : Intraperitoneal bupivacaine $30 \mathrm{~mL} 0.25 \%+$ dexmedetomidine $1 \mathrm{mcg} / \mathrm{kg}$ (diluted in $5 \mathrm{~mL} \mathrm{NS}$ ). Study drugs were prepared by an anaesthesiologist not involved in the study. Anaesthesiologist who observed the patient and surgeon were unaware of the drugs administered to patients of the study group until the end of the study. At the end of the surgery the test solution was given intraperitoneally before removal of trocar in Trendelenburg's position into the hepato-diaphragmatic space, on gall bladder bed and near and above hepatoduodenal ligament. The neuromuscular blockade was antagonised with neostigmine $0.05 \mathrm{mg} / \mathrm{kg}$ and glycopyrrolate $0.01 \mathrm{mg} / \mathrm{kg}$ and trachea was extubated. The nasogastric tube was removed and the patient was shifted to post anaesthesia care unit (PACU). All patients stayed in PACU for 24 hours after the end of surgery. The primary outcome variable was to compare pain (visual analogue scale [VAS]) score. The secondary outcome included time for the first request of analgesia in the postoperative period, total dose of analgesic used in 24 hours period (postoperative) and any adverse/side effects.

\section{Justification of Sample Size}

Sample size was calculated using Raosoft (http://www.rao soft.com/samplesize.html). A total sample size of 135 patients ( $n=45$ each for three groups) was calculated using Power and Sample size calculator (PS version 3.0.0.34), assuming 30\% improvement in pain scores with error of 0.05 and power of $80 \%$.

\section{Statistical Method}

Statistical analysis was performed using Microsoft (MS) Office Excel Software (Microsoft Excel, Redmond, Washington: Microsoft 2003, Computer software). Results were expressed as mean \pm standard deviation, number and percentage (\%). Data were analysed using post-hoc analysis method. Normally, distributed data were assessed using unpaired student's t-test (for comparison of parameters among groups). Comparison was carried out using Chi-square test with a $\mathrm{P}$ value reported at $95 \%$ confidence level. Level of significance used was $\mathrm{P}=0.05$. 


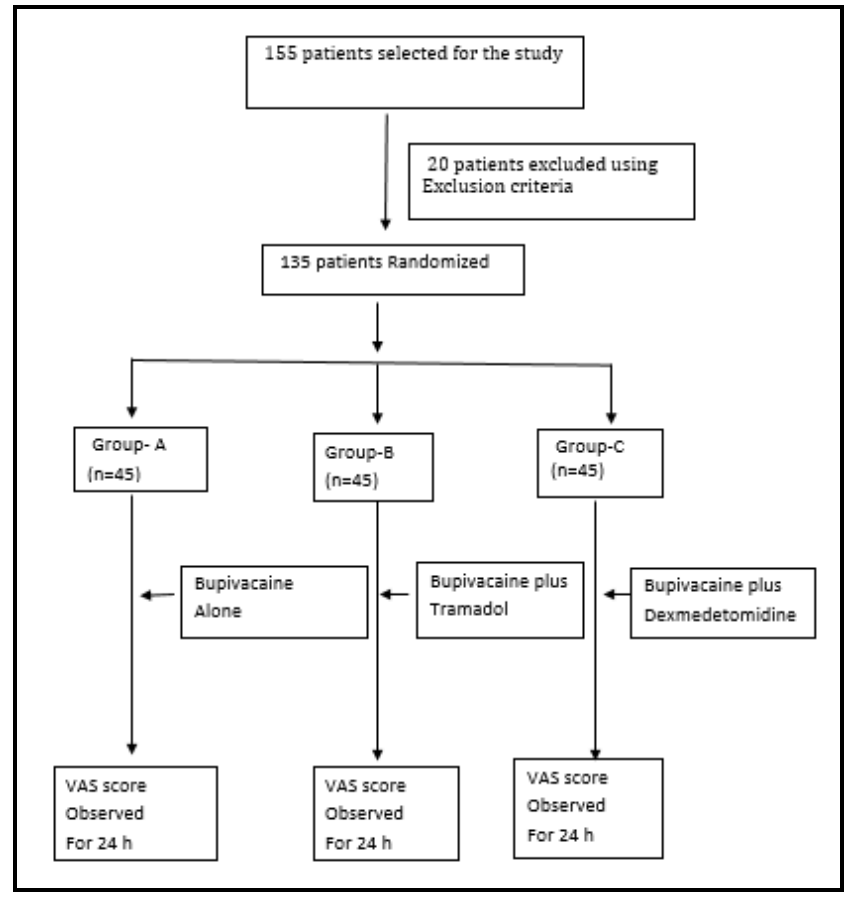

\section{Inclusion Criteria}

(ASA) physical status I - II of both sexes, aged between 18 and 60 years, undergoing laparoscopic cholecystectomies were included.

\section{Exclusion Criteria}

Patients who were allergic to local anaesthetic and study drugs; patients with acute cholecystitis; patients with severe cardiac, pulmonary and neurological diseases; those in whom procedure had to be converted to open cholecystectomy; in whom abdominal drain was put were excluded from the study.

\section{Ethical Issues}

Ethical clearance was sought and obtained from the hospital ethics committee. Besides this written consent was obtained from the patients participating in the study and patient confidentiality was maintained.

\section{RESULTS}

\begin{tabular}{|c|c|c|c|c|}
\hline Time & Group & Mean & P-value & Remarks \\
\hline \multirow{3}{*}{0.5} & A & $5.00 \pm 1.60$ & \multirow{3}{*}{0.021} & \multirow{3}{*}{ Sig } \\
\hline & B & $4.50 \pm 0.90$ & & \\
\hline & $\mathrm{C}$ & $3.00 \pm 0.70$ & & \\
\hline \multirow{3}{*}{1} & $\mathrm{~A}$ & $5.80 \pm 0.09$ & \multirow{3}{*}{0.01} & \multirow{3}{*}{ Sig } \\
\hline & B & $3.50 \pm 1.01$ & & \\
\hline & $\mathrm{C}$ & $2.01 \pm 0.80$ & & \\
\hline \multirow{3}{*}{2} & A & $4.99 \pm 1.00$ & \multirow{3}{*}{0.001} & \multirow{3}{*}{ Sig } \\
\hline & B & $3.01 \pm 0.90$ & & \\
\hline & $\mathrm{C}$ & $2.00 \pm 0.80$ & & \\
\hline \multirow{3}{*}{4} & $\mathrm{~A}$ & $4.45 \pm 1.15$ & \multirow{3}{*}{0.002} & \multirow{3}{*}{ Sig } \\
\hline & B & $2.85 \pm 1.81$ & & \\
\hline & $\mathrm{C}$ & $1.80 \pm 0.22$ & & \\
\hline \multirow{3}{*}{6} & A & $4.10 \pm 0.85$ & \multirow{3}{*}{0.011} & \multirow{3}{*}{ Sig } \\
\hline & B & $2.70 \pm 1.20$ & & \\
\hline & $\mathrm{C}$ & $2.00 \pm 0.15$ & & \\
\hline
\end{tabular}

\begin{tabular}{|c|c|c|c|c|}
\hline \multirow{3}{*}{12} & $\mathrm{~A}$ & $5.00 \pm 0.81$ & \multirow{3}{*}{0.013} & \multirow{2}{*}{ Sig } \\
\cline { 2 - 3 } & $\mathrm{B}$ & $2.50 \pm 0.90$ & \\
& $\mathrm{C}$ & $1.60 \pm 0.50$ & & \multirow{2}{*}{ Sig } \\
\hline \multirow{3}{*}{24} & $\mathrm{~A}$ & $3.00 \pm 0.85$ & \multirow{2}{*}{0.001} & \\
\cline { 2 - 3 } & $\mathrm{B}$ & $2.40 \pm 0.80$ & \\
\cline { 2 - 3 } & $\mathrm{C}$ & $1.05 \pm 0.80$ & & \\
\hline \multicolumn{3}{|c|}{ Table 1. Postoperative VAS Score (mean \pm SD) in } \\
Studied Groups \\
\hline
\end{tabular}

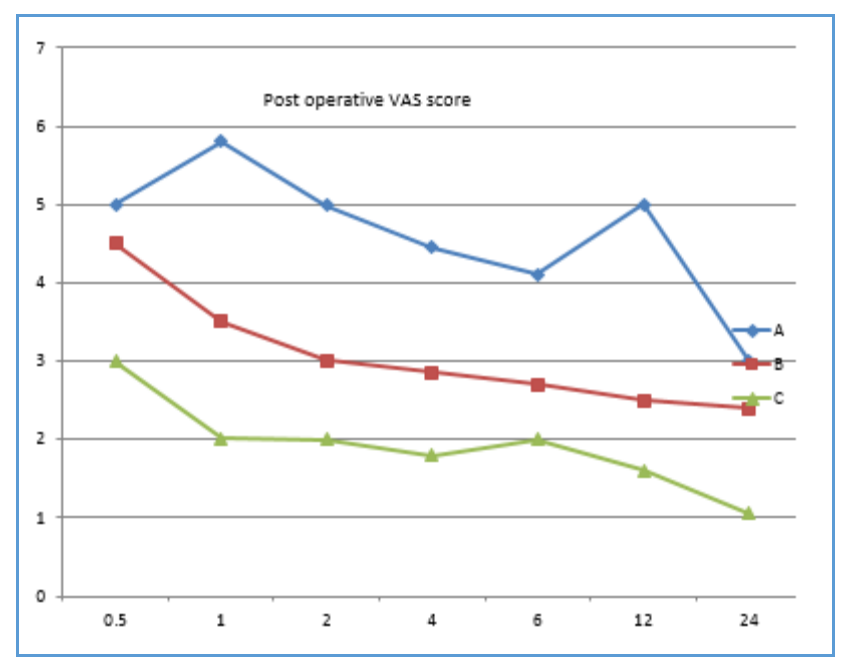

Fig. 1. Graphical Representation of Postoperative VAS Score

\begin{tabular}{|c|c|c|c|c|c|}
\hline Group & $\mathbf{N}$ & Mean & SD & P-value & Remarks \\
\hline A & 45 & $4.4 \pm 0.09$ & 0.09 & 0.02 & Sig \\
\hline B & 45 & $3.00 \pm 0.46$ & 0.46 & 0.01 & Sig \\
\hline C & 45 & $1.78 \pm 0.35$ & 0.35 & 0.007 & Sig \\
\hline \multicolumn{6}{|c|}{ Table 2. Overall VAS over 24h Postoperatively } \\
\hline
\end{tabular}

Furthermore, overall VAS in 24 hours was also significantly lower in Group C (1.78 \pm 0.35$)$ than Group B $(3.00 \pm 0.46)$ and Group A $(4.4 \pm 0.09)$ with a p-value of $<$ 0.001 .

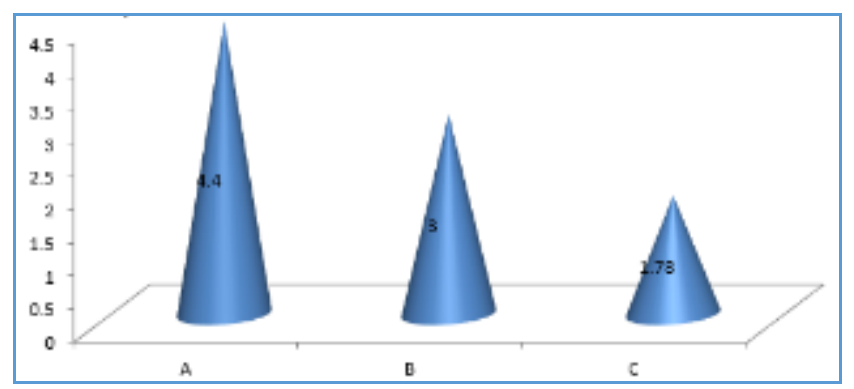

Fig. 2. Overall VAS over 24h Postoperatively

\begin{tabular}{|c|c|c|}
\hline Group Comparison & P-value & Remarks \\
\hline Group A vs Group B & 0.005 & Sig \\
\hline Group A vs Group C & 0.003 & Sig \\
\hline Group B vs Group C & 0.008 & Sig \\
\hline \multicolumn{2}{|c|}{ Table 3. Multiple Comparison (OAVAS), Postoperatively } \\
\hline
\end{tabular}

Above table shows the multiple comparison tests among all the study groups, which were statistically significant with $\mathrm{p}$ value of $(0.012)$. 


\begin{tabular}{|c|c|c|c|c|c|c|}
\hline $\begin{array}{l}\hat{\Xi} \\
\text { ํํㄴ }\end{array}$ & $z$ & $\stackrel{\Xi}{\Xi}$ & ติ & 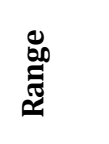 & 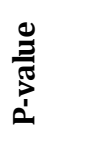 & 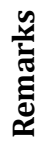 \\
\hline $\mathrm{A}$ & 45 & $56 \pm 19$ & 3.9 & $37-75$ & 0.086 & Sig \\
\hline B & 45 & $119 \pm 23$ & 10.1 & $71-142$ & 0.024 & Sig \\
\hline $\mathrm{C}$ & 45 & $129 \pm 21$ & 11.4 & $75-150$ & 0.045 & Sig \\
\hline
\end{tabular}

$\mathrm{P}=0.004$

The time to first request ranged from 37 - 75 minutes with a mean of $56 \pm 19$ minutes in Group A, 71 - 142 minutes with a mean of $119 \pm 23$ minutes in Group B and $75-150$ minutes with a mean of $129 \pm 21$ minutes in Group C. The statistical difference was significant among the study groups $(\mathrm{p}<0.001)$.

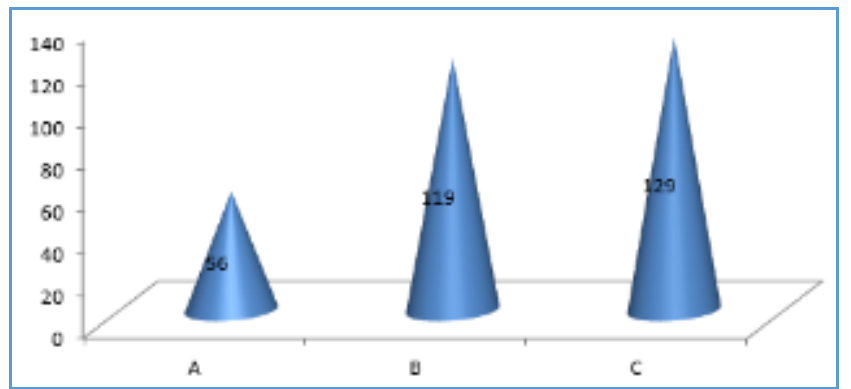

Fig. 3. Time to First Request of Analgesic in Postoperative Period

\begin{tabular}{|c|c|c|}
\hline Group Comparison & P-value & Remarks \\
\hline Group A vs Group B & 0.005 & Sig \\
\hline Group A vs Group C & 0.05 & Sig \\
\hline Group B vs Group C & 0.003 & Sig \\
\hline \multicolumn{2}{|c|}{ Table 5. Multiple Comparisons (TTRA), Time to } \\
Rescue Analgesia \\
\hline
\end{tabular}

Above table shows the multiple comparison tests among all the study groups, which were statistically significant with $p$ value of $(0.049)$.

\begin{tabular}{|c|c|c|c|c|}
\hline Group & Mean & SD & P-value & Remarks \\
\hline A & $170 \pm 70$ & 3.4 & \multirow{2}{*}{0.053} & \multirow{2}{*}{ Sig } \\
\cline { 1 - 3 } B & $80 \pm 30$ & 6.9 & & \\
\cline { 1 - 3 } C & $40 \pm 12$ & 3.2 & & \\
\hline \multicolumn{6}{|r|}{ Table 6. Total Analgesic Dose in First 24h (mg) } \\
\hline
\end{tabular}

Total diclofenac consumption was also lowest in Group C $(40 \pm 12 \mathrm{mg})$ than Group B (80 \pm 30$)$ and Group A (170 \pm 70$)$.

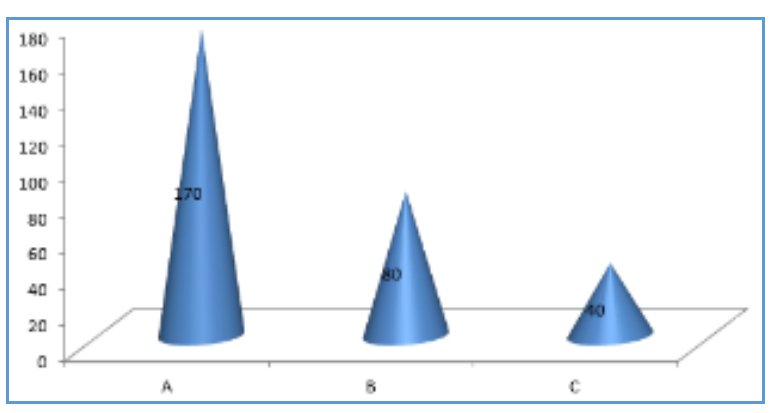

Fig. 4. Total Analgesic Dose in First 24h (mg)

\begin{tabular}{|c|c|c|c|c|c|}
\hline Variables & $\begin{array}{c}\text { Group } \\
\text { A }\end{array}$ & $\begin{array}{c}\text { Group } \\
\text { B }\end{array}$ & $\begin{array}{c}\text { Group } \\
\text { C }\end{array}$ & $\begin{array}{c}\text { P- } \\
\text { value }\end{array}$ & Remarks \\
\hline Nausea & 08 & 06 & 04 & 0.88 & Non Sig \\
\hline Vomiting & 04 & 06 & 0 & 0.66 & Non Sig \\
\hline Shoulder pain & 28 & 16 & 05 & 0.90 & Non Sig \\
\hline Pruritus & 0 & 2 & 0 & 0.40 & Non Sig \\
\hline \multicolumn{7}{|c|}{ Table 7. Postoperative Adverse/Side Effects in } \\
Study Groups \\
\hline
\end{tabular}

The above table shows the postoperative adverse effects observed among the three study groups. When compared statistically, the results were found not significant with a $p$ value of $>0.05$.

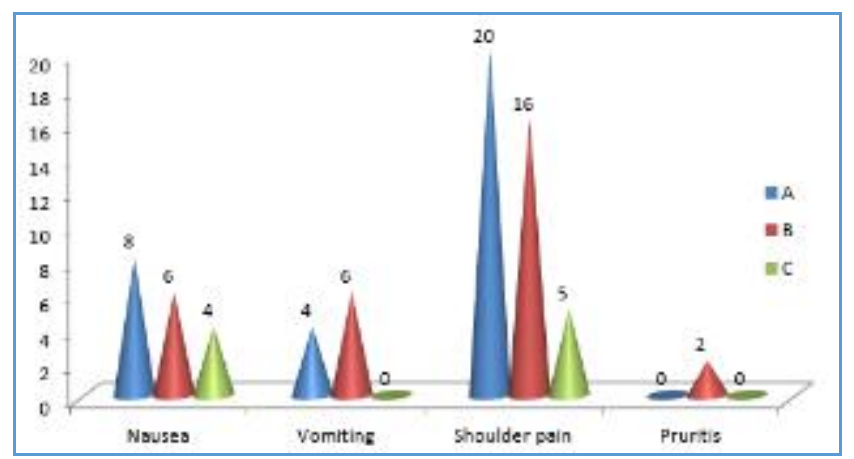

Fig. 5. Postoperative Adverse/Side Effects

\section{DISCUSSION}

Laparoscopic cholecystectomy results in less postoperative pain as compared with open cholecystectomy and pain may be mild or moderate or even severe for some patients. After laparoscopic cholecystectomy patients complain more of visceral pain as a result of stretching of the intra-abdominal cavity, peritoneal inflammation and phrenic nerve irritation caused by residual carbon dioxide in the peritoneal cavity, whereas after open cholecystectomy the type of pain results mostly in parietal pain. ${ }^{31}$ Postoperative abdominal pain usually occurs during the first 24 hours, while shoulder pain most commonly appears on the second day after laparoscopic cholecystectomy. Intraperitoneal (IP) administration of some drugs can be effective for relief of pain after laparoscopic surgery. Some authors suggest that intraperitoneal instillation of drugs for pain relief is effective if used before creation of pneumoperitoneum, ${ }^{32}$ while others conclude that intraperitoneal drug administration is effective at the end of the surgery applied through a trocar. ${ }^{33}$

Postoperative pain after laparoscopic cholecystectomy consists of three components, visceral, parietal and referred shoulder pain distinguishable from each other in intensity, latency and duration. 34 Previous studies 35,36 suggest that predominant cause of pain is parietal, but in contrast many other studies emphasised that in early convalescent period major portion is occupied by visceral pain because as compared to small incisions and limited trauma to the abdominal wall, the surgical manipulation and tissue destruction in visceral organs is much more. $37,38,39$

Multimodal efforts like parenteral opioids, non-steroidal antiinflammatory drugs or local wound infiltration have been done to reduce overall pain and benefit postoperative conditions of patients undergoing laparoscopic surgeries. ${ }^{40-42}$ 
Despite their efficacy with all parenteral medications, there are associated adverse effects.

In this modern era of surgery, intraperitoneal instillation of local anaesthetic agents has become an important method to control postoperative pain, nausea, vomiting and reduced hospital stay.43,44 In laparoscopic surgeries because of gas insufflations and raised intraperitoneal pressure, there is peritoneal inflammation and neuronal rupture with a linear relationship between abdominal compliance and resultant severity of postoperative pain. 45 Hence, we chose intraperitoneal route because it blocks the visceral afferent signals and modifies visceral nociception. The local anaesthetic agents provide antinociception by affecting nerve membrane associated proteins and by inhibiting the release and action of prostaglandins, which stimulates the nociceptors and cause inflammation.46 Intraperitoneal instillation of $0.25 \%$ bupivacaine provide effective analgesia, in addition to this we added either dexmedetomidine or tramadol to compare the antinociceptive efficacy if mixed with bupivacaine.

Golubovic et $\mathrm{al}^{47}$ assessed the analgesic effects of intraperitoneal instillation of bupivacaine and/ or tramadol in patients undergoing laparoscopic cholecystectomy and concluded that intraperitoneal instillation of bupivacaine or tramadol or combination of both are effective method for management of pain after laparoscopic cholecystectomy and they significantly reduce postoperative analgesic and antiemetic medication. We found bupivacaine in combination with tramadol (Group B) has significantly lower VAS score at all points of time $(\mathrm{P}<0.001)$ and overall VAS score and postoperative analgesia was statistically lower than with Group A. But bupivacaine + dexmedetomidine had even better VAS score underlying high efficacy of drug.

Memis et al ${ }^{48}$ studied the effects of tramadol or clonidine added to intraperitoneal bupivacaine, on postoperative pain in total abdominal hysterectomy and found that combination of tramadol or clonidine with intraperitoneal bupivacaine to be more effective than bupivacaine alone. They found no significant difference between tramadol and clonidine groups in terms of efficacy, but we found dexmedetomidine to have significantly better efficacy than tramadol in combination with bupivacaine. The prominent effect of dexmedetomidine may be due to its higher efficacy in our study and higher efficacy of clonidine in the study by Memis et al. 48

There are very few studies in the literature, which examined the analgesic effects of $\alpha-2$ agonists intraperitoneally.

Our results correlate with study done by Ahmed et al,49 which has shown that intraperitoneal instillation of meperidine or dexmedetomidine in combination with bupivacaine $0.25 \%$ significantly decreases the postoperative analgesic requirements and decreased incidence of shoulder pain in patients undergoing laparoscopic gynaecological surgeries.

Time to first request of analgesia in postoperative period was significantly delayed in Group C as compared to Group A $(\mathrm{P}=0.86)$. Memis et $\mathrm{al}^{48}$ found no difference between tramadol or clonidine groups and in present study the time was significantly shorter in tramadol group than dexmedetomidine group $(\mathrm{P}=0.45)$.
Dose of diclofenac required in postoperative period-we found statistically higher doses are required in Group $\mathrm{A}$ as compared to Group C or Group B, $(\mathrm{P}=0.00,0.000$ respectively) which was in agreement with Memis et al and Ahmed et al,50 but by contrast Memis et al48 in their study found higher doses in clonidine group than tramadol group. In our study, no statistically significant difference was found in regard to the adverse effects among the three study groups $(\mathrm{P}=0.88)$. Only $5(12.5 \%)$ patients in Group C suffered from shoulder pain as compared to $16(40 \%)$ in Group B and 28 $(70 \%)$ patients in bupivacaine alone group. Incidence of shoulder pain was also lower in dexmedetomidine group in study done by Ahmed et al. ${ }^{51}$

Multiple studies on the use $\alpha 2$-agonist with analgesic sparing effect have been documented. Dexmedetomidine has been used as an important adjuvant for decreasing analgesia requirement, sedative purpose and anaesthetic sparing effects.

Limitation of the present study is the postoperative pain, which is a subjective experience and can be difficult to quantify objectively when comparing various treatment options. In our study, the use of dexmedetomidine has shown a significant reduction in postoperative pain levels (VAS levels). As there are limited studies in the past, on supplementation of dexmedetomidine to intraperitoneal bupivacaine further studies with different doses of dexmedetomidine, timing and concentrations of local anaesthetics and routes of administration are needed to derive maximal benefit in terms of postoperative pain relief with minimal adverse effects after laparoscopic surgeries.

After getting approval from Institutional Ethical Committee, written informed consent was obtained from all the patients before surgery. One hundred and thirty five patients of (ASA) physical status I - II of both sexes, aged between 18 and 60 years, equally divided into three groups, Group A $(n=45)$, Group B $(n=45)$ and Group C $(n=45)$, undergoing laparoscopic cholecystectomies were included in this prospective study. Patients who were allergic to local anaesthetic and study drugs, patients with acute cholecystitis, patients with severe cardiac, pulmonary and neurological diseases, those in whom procedure had to be converted to open cholecystectomy and in whom abdominal drain was put were excluded from the study.

Patients were randomly allocated to one of the groups using table of randomisation, Group A $(n=45)$ : Intraperitoneal bupivacaine $30 \mathrm{~mL} 0.25 \%+5 \mathrm{~mL}$ normal saline (NS), Group B ( $n=45)$ : Intraperitoneal bupivacaine 30 $\mathrm{mL} 0.25 \%$ + tramadol $1 \mathrm{mg} / \mathrm{kg}$ (diluted in $5 \mathrm{~mL} \mathrm{NS}$ ) or Group C ( $\mathrm{n}=45)$ : Intraperitoneal bupivacaine $30 \mathrm{~mL} 0.25 \%+$ dexmedetomidine $1 \mathrm{mcg} / \mathrm{kg}$ (diluted in $5 \mathrm{~mL} \mathrm{NS}$ ).

On arrival to operating room, an 18-gauge intravenous (IV) catheter was inserted and $6 \mathrm{~mL} / \mathrm{kg} / \mathrm{h}$ crystalloid was infused intraoperatively, monitoring of electrocardiography, non-invasive blood pressure, oxygen saturation (SpO2) was started and baseline values were recorded. Pre-oxygenation with $100 \%$ oxygen (02) was done for 3 mins. General anaesthesia was induced with IV propofol $2.0-2.5 \mathrm{mg} / \mathrm{kg}$ followed by succinylcholine $2 \mathrm{mg} / \mathrm{kg}$ to facilitate orotracheal intubation. The trachea was intubated with a cuffed orotracheal tube of appropriate size and lubricated with 
lidocaine jelly $2 \%$. Anaesthesia was maintained with $60 \%$ $\mathrm{N} 20$ in oxygen with $0.5 \%-1 \%$ isoflurane. Intermittent boluses of atracurium bromide were used to achieve muscle relaxation. Minute ventilation was adjusted to maintain normocapnia (end tidal carbon dioxide [EtCO2] between 34 and $38 \mathrm{mmHg}$ ) and EtCO2 was monitored. Nasogastric tube of appropriate size was inserted.

All patients stayed in PACU for 24 hours after the end of surgery. The primary outcome variable was to compare pain (visual analogue scale [VAS]) score. The secondary outcome included time for the first request of analgesia in the postoperative period, total dose of analgesic used in 24 hours period (postoperative) and any adverse/ side effects.

The intensity of postoperative pain was recorded for all the patients using VAS score at 0.5, 1, 2, 4, 6, 12 and 24 hours after surgery and overall VAS score (mean of all VAS scores). All the study patients were instructed about the use of the VAS score before induction of anaesthesia (VAS score 0- no pain, VAS score 10- worst possible pain). Patients who reported VAS 3 or $>3$ were given diclofenac $75 \mathrm{mg}$ intramuscularly as rescue analgesia. Patients were also observed for postoperative nausea and vomiting. Patients who suffered nausea or vomiting were given ondansetron 4 mg IV. Time to the first request of analgesia (considering the extubation as time 0 ), total dose of analgesia and adverse or side effects over 24 hours postoperatively were noted. There was no significant difference between the three groups regarding age, sex distribution, ASA class and duration of surgery.

There was a significant difference regarding time to rescue analgesia and the total dose of rescue analgesics required during the postoperative 24 hours in Group C (dexmedetomidine) as compared to other study groups.

There was no significant difference found regarding vital parameters (heart rate, blood pressure, respiratory rate, oxygen saturation) and adverse effects (nausea, vomiting, respiratory depression, pruritus and urinary retention) during the postoperative period up to 24 hours.

\section{CONCLUSION}

We conclude that intraperitoneal instillation of dexmedetomidine $1 \mathrm{mcg} / \mathrm{kg}$ in combination with bupivacaine $0.25 \%$ in elective laparoscopic cholecystectomy significantly reduces the postoperative pain and significantly reduces the analgesic requirement in postoperative period as compared to bupivacaine $0.25 \%$ alone and may be better than bupivacaine combined with tramadol.

\section{REFERENCES}

[1] Shukla U, Prabhakar T, Malhotra K, et al. Intraperitoneal bupivacaine alone or with dexmedetomidine or tramadol for post-operative analgesia following laparoscopic cholecystectomy: a comparative evaluation. 2017;IP:169.149.7.56 http://www.ijaweb.org

[2] Rademaker BM, Ringers J, Odoom JA, et al. Pulmonary function and stress response after laparoscopic cholecystectomy: comparison with subcostal incision and influence of thoracic epidural analgesia. Anesthesia and Analgesia 1992;75(3):381-5.
[3] Joris J, Cigarini I, Legrand $\mathrm{M}$, et al. Metabolic and respiratory changes after cholecystectomy performed via laparotomy or laparoscopy. $\mathrm{Br} \mathrm{J}$ Anaesth 1992;69(4):341-5.

[4] Lord Mc Coll. Laparoscopic cholecystectomy. Am R Coll Surg Engl 1992; 74:231.

[5] Rees BI, Williams HR. Laparoscopic cholecystectomy: the first 155 patients. Am R Coll Surg Eng, 1992;74(4): 233-6.

[6] Scott AD, Greville AC, McMillan L, et al. Laparoscopic laser cholecystectomy results of the technique in 210 patients. Am R Coll Surg Engl 1992;74(4):237-41.

[7] Brennan TJ. Postoperative models of nociception. ILAR J 1999;40(3):129-36.

[8] Sherwinter DA, Ghaznavi AM, Spinner D, et al. Continous infusion of intraperitoneal bupivacaine after laparoscopic surgery: a randomized controlled trial. Obes Surg 2008;18(12):1581-6.

[9] Brennan TJ. Postoperative models of nociception. ILAR J 1999;40(3):129-36.

[10] Allegri M, Clark MR, De Andres J, et al. Acute and chronic pain: where we are and where we have to go. Minerva Anestesiol 2012;78(2):222-35.

[11] Scott NB. Wound infiltration for surgery. Anaesthesia 2010;65(Suppl 1):67-75.

[12] Sweitzer SM, Fann SA, Borg TK, et al. Trials, tribulations and triumphs of a pilot initiative to optimize the management of wounds. Diabetes Educ 2006;32(2):197-210.

[13] Johnson RC, Hedges AR, Morris R, et al. Ideal pain relief following laparoscopic cholecystectomy. Int J Clin Pract 1999;53(1):16-8.

[14] Brower MC, Johnson ME. Efficacy of continous local anaesthetic infusion for postoperative pain after radical retropubic prostatectomy. Reg Anesth Pain Med 2003;28(3):233-40.

[15] Hilvering B, Draaisma WA, van der Bilt JD, et al. Randomized clinical trial of combined preincisional infiltration and intraperitoneal instillation of levobupivacaine for postoperative pain after laparoscopic cholecystectomy. Br J Surg 2011;98(6):784-9.

[16] Lohsiriwat V, Lert-akyamanee N, Rushatamukayanunt W. Efficacy of pre-incisional bupivacaine infiltration on postoperative pain relief after appendectomy: a prospective double blind randomized trial. World J Surg 2004;28(10):947-50.

[17] Sihoe AD, Manlulu AV, Lee TW, et al. Pre-emptive local anesthesia for needlescopic video-assisted thoracic surgery: a randomized controlled trial. Eur J Cardiothorac Surg 2007;31(1):103-8.

[18] Brower MC, Johnson ME. Adverse effects of local anesthetic infiltration on wound healing. Reg Anesth Pain Med 2003;28(3):233-40.

[19] Fitzpatrick CL, Weir HL, Monnet E. Effects of infiltration of the incision site with bupivacaine on postoperative pain and incisional healing in dogs undergoing ovariohysterectomy. J Am Vet Med Assoc 2010;237(4):395-401. 
[20] Arikan OK, Ozcan S, Kazkayasi M, et al. Does preincisional injection of levobupivacaine with epinephrine have any benefits for children undergoing tonsillectomy? An individual evaluation. J Otolaryngol 2006;35(3):167-72.

[21] Becker DE, Reed KL. Local anaesthetics: review of pharmacological considerations. Anesth Prog 2012;59(2):90-101, quiz 102-3.

[22] El-Labban GM, Hokkam EN, El-Labban MA, et al. Incisional versus intraperitoneal infiltration of local anaesthetics for controlling early post-laparoscopic cholecytectomy pain. J Minim Access Surg 2011;7(3):173-7.

[23] Ahmed B, Elmawgoud AA, Dosa R. Antinociceptive effect of ( $\alpha$-2 adrenoceptor agonist) dexmedetomidine vs meperidine, topically, after laproscopic gynecologic surgery. J Med Sci 2008;8:400-4.

[24] Golubovic S, Golubovic V, Cindric-Stancin M, et al. Intraperitoneal analgesia for laparoscopic cholecystectomy: bupivacaine versus bupivacaine with tramadol. Coll Antropol 2009;33(1):299-302.

[25] Memis D, Turan A, Karamanlioglu B, et al. The effect of tramadol or clonidine added to intraperitoneal bupivacaine on post operative pain in total abdominal hysterectomy. Opioid Manag 2005;1(2):77-82.

[26] Fredman B, Jedeikin R, Olsfanger D, et al. Residual pneumoperitoneum: a cause of postoperative pain after laparoscopic cholecystectomy. Anesth Analg 1994;79(1):152-4.

[27] Barczynski M, Konturek A, Herman Rm. Superiority of preemptive analgesia with intraperitoneal instillation of bupivacaine before rather than after the creation of pneumoperitoneum for laparoscopic cholecystectomy: a randomized, double-blind, placebo-controlled study. Surg Endosc 2006;20(7):1088-93.

[28] Kocamanoglu IS, Kelsaka E, Malatyalioglu E, et al. Intraperitoneal analgesia for laparoscopic cholecystectomy. 2005:53-7.

[29] Dubois F, Icard P, Berthelot G, et al. Coelioscopic cholecystectomy. Preliminary report of 36 cases. Ann Surg 1990;211(1):60-2.

[30] Golubovic S, Golubovic V, Cindric-Stancin, et al. Analgesic effect of intraperitoneal tramadol during laparoscopic cholecystectomy. Period Biol 2007;109:317-20.

[31] Fredman B, Jedeikin R, Olsfanger D, et al. Residual pneumoperitoneum: a cause of postoperative pain after laparoscopic cholecystectomy. Anesth Analg 1994;79(1):152-4.

[32] Barczynski M, Konturek A, Herman Rm. Superiority of preemptive analgesia with intraperitoneal instillation of bupivacaine before rather than after the creation of pneumoperitoneum for laparoscopic cholecystectomy: a randomized, double-blind, placebo-controlled study. Surg Endosc 2006;20(7):1088-93.

[33] Coughlin SM, Karanicolas PJ, Emmerton-Coughlin HM, et al. Better late than never? Impact of local analgesia timing on postoperative pain in laparoscopic surgery: a systematic review and metat analysis. Surg Endosc 2010;24(12):3167-76.
[34] Hernandez-Palazon J, Tortosa JA, de la Rosa NV, et al. Intraperitoneal application of bupivacaine plus morphine for pain relief after laparoscopic cholecystectomy. Eur J Anaesthesiol 2003;20(11):8916.

[35] Verma GR, Lyngdoh TS, Kaman L, et al. Placement of $0.5 \%$ bupivacaine-soaked surgical in the gallbladder bed is effective for pain after laparoscopic cholecystectomy. Surg Endosc 2006;20(10):1560-4.

[36] Cantore F, Boni L, Di Giuseppe M, et al. Pre-incision local infiltration with levobupivacaine reduces pain and analgesic consumption after laparoscopic cholecystectomy: a new device for day-case procedure. Int J Surg 2008;6(Suppl 1):S89-92.

[37] Karaaslan D, Sivaci RG, Akbulut G, et al. Preemptive analgesia in laparoscopic cholecystectomy: a randomized controlled study. Pain Pract 2006;6(4):237-41.

[38] Pappas-Gogos G, Tsimogiannis KE, Zikos N, et al. Preincisional and intraperitoneal ropivacaine plus normal saline infusion for postoperative pain relief after laparoscopic cholecystectomy: a randomized double-blind controlled trial. Surg Endosc 2008;22(9):2036-45.

[39] Papadima A, Lagoudianakis EE, Antonakis P, et al. Repeated intraperitoneal instillation of levobupivacaine for the management of pain after laparoscopic cholecystectomy. Surgery 2009;146(3):475-82.

[40] El-Labban GM, Hokkam EN, El-Labban MA, et al. Incisional versus intraperitoneal infiltration of local anaesthetics for controlling early post-laparoscopic cholecytectomy pain. J Minim Access Surg 2011;7(3):173-7.

[41] Tobias JD. Preliminary experience with transverses abdominis plane block for postoperative pain relief in infants and children. Saudi J Anaesth 2013;7:3-4.

[42] Abdulla S, Eckhardt R, Netter U, et al. A randomized, double-blind, controlled trial on non-opioid analgesics and opioid consumption for postoperative pain relief after laparoscopic cholecystectomy. Acta Anaesthesiol Belg 2012;63(1):43-50.

[43] Salihoglu Z, Yildirim M, Demiroluk S, et al. Evaluation of intravenous paracetamol administration on postoperative pain and recovery characteristics in patients undergoing laparoscopic cholecystectomy. Surg Laparosc Endosc Percutan Tech 2009;19(4):3213.

[44] Kahokehr A, Sammour T, Soop M, et al. Intraperitoneal local anaesthetic in abdominal surgery - a systemic review. ANZ J Surg 2011;81(4):237-45.

[45] Bharadwaj N, Sharma V, Chari P. Intraperitoneal bupivacaine instillation for postoperative pain relief after laparoscopic cholecystectomy. Indian J Anaesth 2002;46(1):49-52.

[46] Liu SS, Hodgson PS. Local anaesthetics. In: Barash PG, Cullen BF, Stoelting RK. eds. Clinical anaesthesia. 4th edn. Philadelphia: Lippicott Williams and Wilkins 2001:449-69. 
[47] Golubovic S, Golubovic V, Tokmadzic VS. Intraperitoneal analgesia for laproscopic cholecystectomy. Periodicum Biologorum 2009;3:2636.

[48] Memis D, Turan A, Karamanlioglu B, et al. The effect of tramadol or clonidine added to intraperitoneal bupivacaine on post operative pain in total abdominal hysterectomy. Opioid Manag 2005;1(2):77-82.

[49] Ahmed B, Elmawgoud AA, Dosa R. Antinociceptive effect of ( $\alpha$-2 adrenoceptor agonist) dexmedetomidine vs meperidine, topically, after laproscopic gynecologic surgery. J Med Sci 2008;8:400-4.
[50] Jamal A, Usmani H, Khan MM, et al. Intraperitoneal preinsufflation of $0.125 \%$ bupivacine with tramadol for postoperative pain relief following laparoscopic cholecystectomy. J Anaesthesiol Clin Pharmacol 2016;32(2):257-60.

[51] Oza VP, Parmar V, Badheka J, et al. Comparative study of postoperative analgesic effect of intraperitoneal instillation of dexmedetomidine with bupivacaine and bupivacaine alone after laparoscopic surgery. J Minim Access Surg 2016;12(3):260-4. 